American Journal of Pharmaceutical Education 2020; 84 (5) Article 7550.

\title{
RESEARCH
}

\section{Using the Theory of Planned Behavior to Evaluate Factors That Influence PharmD Students' Intention to Attend Lectures}

\author{
Erik Skoglund, PharmD, ${ }^{\mathrm{a}}$ Julianna Fernandez, PharmD, ${ }^{\mathrm{b}}$ Jeffrey T. Sherer, PharmD, MPH, \\ Elizabeth A. Coyle, PharmD, ${ }^{\mathrm{b}}$ Kevin W. Garey, PharmD, MS, ${ }^{\mathrm{b}}$ Marc L. Fleming, PhD, MPH, ${ }^{\mathrm{c}}$ \\ Amelia K. Sofjan, PharmD ${ }^{b}$ \\ ${ }^{\text {a }}$ Western University of Health Sciences College of Pharmacy, Pomona, California \\ ${ }^{\mathrm{b}}$ University of Houston College of Pharmacy, Houston, Texas \\ ${ }^{\mathrm{c}}$ University of North Texas System College of Pharmacy, Fort Worth, Texas \\ Submitted February 7, 2019; accepted September 29, 2019; published May 2020.
}

Objective. To use the theory of planned behavior (TPB) to evaluate the contribution of attitude, subjective norm, and perceived behavioral control in predicting students' intention to attend class lectures in a Doctor of Pharmacy (PharmD) curriculum in which lecture recordings were available.

Methods. A survey instrument based on the TPB was developed from focus groups with PharmD students. The survey was then distributed to first through third year students at the conclusion of the 2017-2018 academic school year. Respondents were asked to evaluate their beliefs regarding lecture attendance and their intention to attend lectures during the upcoming fall semester. Predictors of intention were evaluated using descriptive statistics and multiple logistic regression analyses.

Results. Responses from 198 of 383 students contained usable data (52\% effective response rate). The TPB constructs of attitude and subjective norm were predictors of high intention to attend lectures. Students with a positive attitude towards lecture attendance (eg, believed that purposeful active learning is desirable and occurs during class) were nearly $30 \%$ more likely to have high intention to attend lectures. Students with a positive subjective norm (ie, perceived social pressure from professors and classmates to attend lectures) were $66 \%$ more likely to have high intention to attend lectures. Perceived behavioral control was not associated with high intention to attend lectures.

Conclusion. Interventions aimed at improving students' attitudes and subjective norm may be beneficial in improving students' intention to attend class lectures.

Keywords: absenteeism, recording, pharmacy, student, attendance

\section{INTRODUCTION}

Class absenteeism is common in higher education and healthcare professions schools. An average lecture attendance of 50\%-60\% has been reported among medical, nursing, and pharmacy programs worldwide..$^{1-4}$ Some studies have shown an association between absenteeism and decreased academic achievement and lower student engagement, ${ }^{5-8}$ but others have identified weak or no association between absenteeism and student performance. ${ }^{9-11}$ Regardless, decreased lecture attendance

Corresponding Author: Amelia K. Sofjan, University of Houston College of Pharmacy, 4849 Calhoun Rd., Rm. 4025, Houston, TX 77204-5039. Tel: 713-743-6429. Fax: 832-8428383. Email: aksofjan@uh.edu.

Note: Dr. Skoglund was an infectious diseases fellow and Dr. Fleming was an associate professor at the University of Houston College of Pharmacy during the time this study was conducted. among healthcare professional students is a concern among many faculty members. ${ }^{2,12,13}$

In studies where asynchronous video recordings of lectures were not yet available to healthcare professions students, factors such as the ability to take one's own notes or the instructor highlighting important points were among the top cited reasons to attend. ${ }^{4,14}$ With the availability of recordings, these reasons were no longer top motivators for students to come to class, and their decision of whether to come to class involved a more complex "cost-benefit analysis.",15-19 Lecture attendance was driven more by the anticipated benefit of attendance on learning, a desire to show professionalism, the lecturer's ability to teach, and use of class time. ${ }^{1,15-19}$ As more pharmacy schools are shifting towards active learning and assessing higher-order thinking skills, students who solely watch recordings may not perform as well as those who attend class and participate in active 


\section{American Journal of Pharmaceutical Education 2020; 84 (5) Article 7550.}

learning. ${ }^{20,21}$ In an active-learning environment, students get the opportunity to practice higher-order thinking skills, engage in collaborative learning, take risks, and/or learn teamwork skills. ${ }^{21,22}$ As the majority of pharmacy faculty members in the United States employ activelearning strategies in the classroom, students need to attend class to experience the benefits of active learning. ${ }^{21,23}$

Previous studies have described many factors that influence attendance, ${ }^{1,4,14-17}$ but it is unclear which factors are most determinant of attendance and which interventions can best improve attendance. Previous studies were also not based on a theoretical framework. Use of a theoretical framework allows the investigator to examine a phenomenon through a specific lens and provides a "blueprint" that anchors the study methods and analysis. ${ }^{24}$ One such framework that has been previously used to understand student and faculty behaviors is the theory of planned behavior (TPB). ${ }^{25-27}$ A central principle of the TPB is that a person's intention to act is an immediate determinant of their planned behavior. According to the TPB, intention is predicted by three constructs: attitude (perceived consequences of performing a behavior), subjective norm (perceived social pressure to perform the behavior), and perceived behavioral control (the extent to which a person feels able or not able to enact a behavior). ${ }^{28}$ These constructs are further explained by three underlying beliefs. Behavioral beliefs (beliefs about the consequences of a behavior) explain attitude; normative beliefs (beliefs about how people important to the person want him or her to behave) explain subjective norm; and control beliefs (beliefs about factors that facilitate or impede a behavior) explain perceived behavioral control (Figure 1). ${ }^{28,29}$

Our primary objective was to use the TPB to evaluate the contribution of attitude, subjective norm, and perceived behavioral control in predicting students' intention to attend class lectures in a PharmD curriculum in which recordings were available. A secondary objective was to elucidate underlying beliefs that explain students' overall attitude, subjective norm, and perceived behavioral control regarding attendance in order to identify those interventions that are most likely to improve attendance.

\section{METHODS}

This study was approved by the institutional review board at the University of Houston and was conducted at the University of Houston College of Pharmacy among students enrolled in a four-year PharmD program. Students in the didactic portion of the curriculum (first-, second-, and third-year students) during the 2017-2018 academic school year were included. At the time of this study, an attendance policy did not exist. Lecture attendance was expected but not mandated or routinely monitored. In-class participation points, pop quizzes, and active learning were employed, but the extent to which they occurred varied between courses. Recording of lectures was implemented in fall 2015, and the lectures were made available online via Mediasite (Sonic Foundry Media Systems Inc., Madison, WI) in 22 of 27 non-skills laboratory-based didactic courses during the study period. Students could access recordings anytime anywhere throughout each semester.

An exploratory, sequential, mixed-methods approach was used. ${ }^{30}$ The first qualitative phase of the study allowed researchers to garner beliefs regarding attendance among a small sample of PharmD students. ${ }^{31}$ The students were randomly selected and invited via email to participate in focus groups. A focus group guide with standardized open-ended questions was used to elicit behavioral, normative, and control beliefs related to lecture attendance (Table 2). ${ }^{31-34}$ Participation was voluntary, and participants gave permission to audio record the discussions. No personal identifiers were linked with the recordings. Two focus groups were conducted with a total

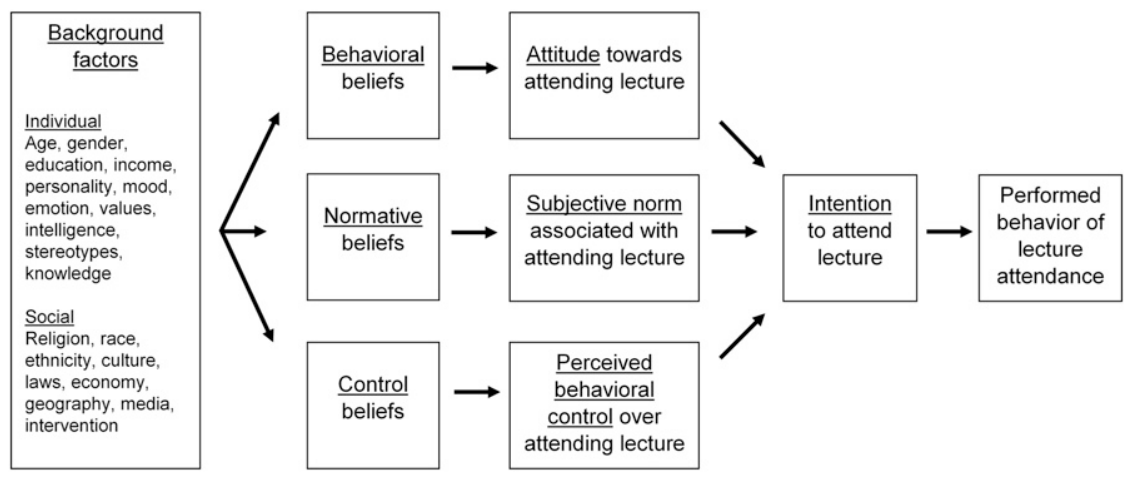

Figure 1. The Theory of Planned Behavior Model Used in This Study to Evaluate the Contribution of Attitude, Subjective Norm, and Perceived Behavioral Control in Predicting Doctor of Pharmacy Students' Intention to Attend Class Lectures. Adapted from Ajzen. ${ }^{28,29}$ 


\section{American Journal of Pharmaceutical Education 2020; 84 (5) Article 7550.}

of nine second- and third-year PharmD students. Beliefs that were expressed by at least two students were considered modal and were used to construct a survey instrument for use in the second phase of the study. ${ }^{32,35}$

In the second phase, a survey instrument was designed in accordance with the TPB to quantitatively evaluate factors that influence students' intention to attend lectures among a larger sample of PharmD students. $^{28,31}$ The survey contained demographic questions to provide context. Behavioral intention, the dependent variable for the primary objective, was assessed by the following item: "I intend to attend lecture [sic] next semester." Predictors of intention (attitude, subjective norm, and perceived behavioral control) were assessed directly and indirectly. ${ }^{31}$ Direct and indirect measures of these three constructs were created based on Ajzen's guidelines and Francis' instructions for TPB questionnaire development. ${ }^{28,31}$

Direct measures of attitude were assessed based on three items, subjective norm was assessed based on two items, and perceived behavioral control was assessed based on two items (Table 3). For instance, attitude was measured directly by asking participants the value of attending lectures on a response scale ranging from "useless" to "worthwhile." " Indirect measures of attitude (seven items), subjective norm (two items), and perceived behavioral control (six items) were constructed based on modal behavioral, normative, and control beliefs, respectively, which were identified during the first phase of the study (Tables 2 and 3). ${ }^{31,32} \mathrm{~A}$ pair of survey items was formulated for each modal belief identified. Attitude was measured indirectly by asking students about the strength of behavioral beliefs and outcome evaluations (eg, likelihood for lecturers to read directly from slides and how undesirable or desirable this practice was). Subjective norm was measured indirectly by asking about the strength of normative beliefs and students' motivation to comply (eg, whether professors expect them to attend lectures and how much they want to comply with this expectation). Perceived behavioral control was measured indirectly by asking students about the likelihood of control beliefs to occur and their perceived power to facilitate or impede attendance (eg, likelihood of having work obligations that conflict with lectures and whether this factor facilitates or hinders attendance).

Survey items were answered on a seven-point semantic differential scale (from 1 to 7 or -3 to +3 ). A response of 1 or -3 was associated with the least favorable opinion and a response of 7 or +3 was associated with the most favorable opinion. A direct composite score for each construct (attitude, subjective norm, perceived behavioral control) was calculated by adding scores from all direct items within each construct.

The survey instrument was piloted by 10 students from the first-, second-, and third-year classes. Minor modifications to the survey were made based on their feedback. The final survey instrument was hosted online via Qualtrics (Provo, UT) and a link was emailed to PharmD students after the end of the academic year (early June 2018). Students were asked to answer questions with respect to their planned behavior regarding lecture attendance for the upcoming fall courses. Third-year students who would be starting advanced pharmacy practice experience in the fall were instructed to answer questions as if they were continuing in the didactic curriculum. The survey was voluntary and anonymous and required 10-15 minutes to complete. No incentive was provided for completing the survey. Five reminder emails were sent over the two-week period in which the survey remained open. ${ }^{36}$

In the first phase of the study, we conducted a deductive content analysis based on the TPB. ${ }^{37,38}$ Focus group discussions were transcribed verbatim. A categorization matrix consisting of six categories/themes as per the TPB was created: advantages and disadvantages of attending lectures (behavioral beliefs), those who approve or disapprove of attending lectures (normative beliefs), and factors that facilitate or hinder attending lectures (control beliefs). Two researchers separately read and re-read the transcripts. Comments were broken into segments and coded into subcategories representing the beliefs of the participants. The researchers reconciled differences in their lists of subcategories and created a final list of subcategories. The comments were coded into the final subcategories (beliefs) and were grouped into the six categories/themes. Modal beliefs were reported in descending order (Table 2).

In the second phase of the study, descriptive statistics were calculated for each survey item. Data were presented as medians (interquartile range) and assessed using nonparametric statistics because of non-normality. The validity of direct and indirect measures was assessed by calculating correlations between indirect composite scores and their respective direct composite scores using Spearman's rho. ${ }^{28,31}$ The reliability of direct measures within each construct was confirmed if the Cronbach $\alpha$ was $>.7$ or if the Spearman rho was significant $(p<.05)$ for constructs with less than three items. ${ }^{39}$ Analysis of reliability of indirect measures was not performed because various beliefs may be inconsistent with each other. $^{28}$

To assess our primary objective, direct composite scores of attitude, subjective norm, and perceived 


\section{American Journal of Pharmaceutical Education 2020; 84 (5) Article 7550.}

behavioral control were correlated with intention by calculating Spearman rho. Respondents were divided into high and low intention groups based on the median response to the statement, "I intend to attend lecture [sic] next semester," which was a 5 on a range of 1 to 7 . Hence, responses $>5$ were classified as high intention and responses of $\leq 5$ were classified as low intention. Multiple logistic regression was used to assess the influence of each construct (attitude, subjective norm, perceived behavioral control) on high intention by simultaneously forcing all of the variables into the model. ${ }^{31}$ Demographic variables were excluded from the regression model because their effects were accounted for in the TPB model through the influence they asserted over the students' behavioral, normative, and control beliefs (Figure 1). ${ }^{28,29}$ To assess the secondary objective, multiple logistic regressions were used to identify behavioral, normative, or control beliefs that were predictive of high direct composite scores for attitude, subjective norm, and perceived behavioral control, respectively. Statistical analyses were performed on SPSS Statistics for Windows v. 25 (IBM Corp., Armonk, NY).

\section{RESULTS}

The focus group discussions yielded many modal beliefs that informed students' attitude, subjective norm, and perceived behavioral control (Table 2). Modal behavioral beliefs $(n=16)$ were more numerous than normative beliefs $(n=3)$ or control beliefs $(n=8)$. Modal beliefs were used to construct the indirect measures of each construct in the final survey.

Of the 383 first- through third-year PharmD students enrolled, 240 responded to the survey (63\% response rate). Of these, 198 entries were fully completed and contained usable data (52\% effective response rate). Similar to class demographics, respondents were mostly female students in their early twenties, and a little over half held a previous bachelor's degree (Table 1). A majority of respondents had a job and participated in student organizations. The students' median one-way commute time to campus was half an hour. The validity of direct and indirect measures of attitude and subjective norm was confirmed based on the correlations between indirect composite scores of each construct and their respective direct composite scores: Spearman rho, $r_{s}, 0.50(p<.001)$ and $0.49(p<.001)$, respectively. The validity of indirect measures of perceived behavioral control was not confirmed as the correlation between indirect and direct composite scores of perceived behavioral control was not significant: Spearman rho, $r_{s}, 0.074(p=\mathrm{NS})$. The reliability of direct measures within each construct was confirmed: the Cronbach $\alpha$ coefficient for attitude items was 0.88 and the Spearman rho, $r_{s}$, for subjective norm items was $0.49(p<.001)$, and 0.27 for perceived behavioral control items $(p<.001)$.

With respect to our primary objective, we found that 96 respondents had high intention to attend lectures (ie, response of $>5$ out of 7 in response to the statement "I intend to attend lecture next semester."), while 102 students had low intention to attend lectures. Respondents had a moderately positive attitude towards attending lectures (median attitude composite score of 15 out of a possible score range of 3 to 21), felt moderate social pressure to attend lectures (median subjective norm composite score of 10 out of a possible score range of 2 to 14), and felt capable of attending lectures (median perceived behavioral control composite score of 12 out of a possible score range of 2 to 14) (Table 3). Attitude and subjective norm were highly correlated with intention (Spearman rho, $r_{s}, 0.74$ and 0.76 , respectively), while perceived behavioral control was not as highly correlated with intention $\left(r_{s}, 0.41\right)$. Nevertheless, significance was confirmed in each instance $(p<.001)$ (Table 4$)$. In the logistic regression model, only attitude and subjective norm were predictors of high intention to attend lectures (Table 5).

To assess our secondary objective (ie, elucidate beliefs that explain each construct), two multiple logistic regressions were performed. Model 1 assessed which behavioral beliefs were predictive of a favorable attitude. Model 2 assessed which normative beliefs were predictive of a strong positive subjective norm. We did not analyze which control beliefs were predictive of a strong perceived behavioral control because the validity of the control belief items was not confirmed, as explained above, and perceived behavioral control was not predictive of intention. Attitude was classified as favorable or unfavorable based on the median attitude composite score (15 out of 21$)$. Behavioral beliefs that were predictive of a favorable attitude towards attending lectures (ie, an attitude composite score of $\geq 15$ out of 21 ) included the belief that attending lectures would result in less study time for that particular lecture material (AOR 1.13, 95\% CI 1.081.19) and the belief that lectures contain interactive exercises with relevant applications (AOR 1.12, 95\% CI 1.04-1.20). Positive subjective norm was classified as weak vs strong based on the median subjective norm composite score (10 out of 14). Normative beliefs that were predictive of a strong positive subjective norm towards attending lectures (ie, a subjective norm composite score of $\geq 10$ out of 14) were perceived expectations of professors (AOR 1.24, 95\% CI 1.16-1.33) and classmates (AOR 1.10, 95\% CI 1.03-1.18).

\section{DISCUSSION}

This study reports the first use of the TPB to assess predictors of student intention to attend lectures in a 


\section{American Journal of Pharmaceutical Education 2020; 84 (5) Article 7550.}

Table 1. Demographics of Doctor of Pharmacy Students Who Completed a Survey That Evaluates Factors Influencing Their Intention to Attend Class Lectures

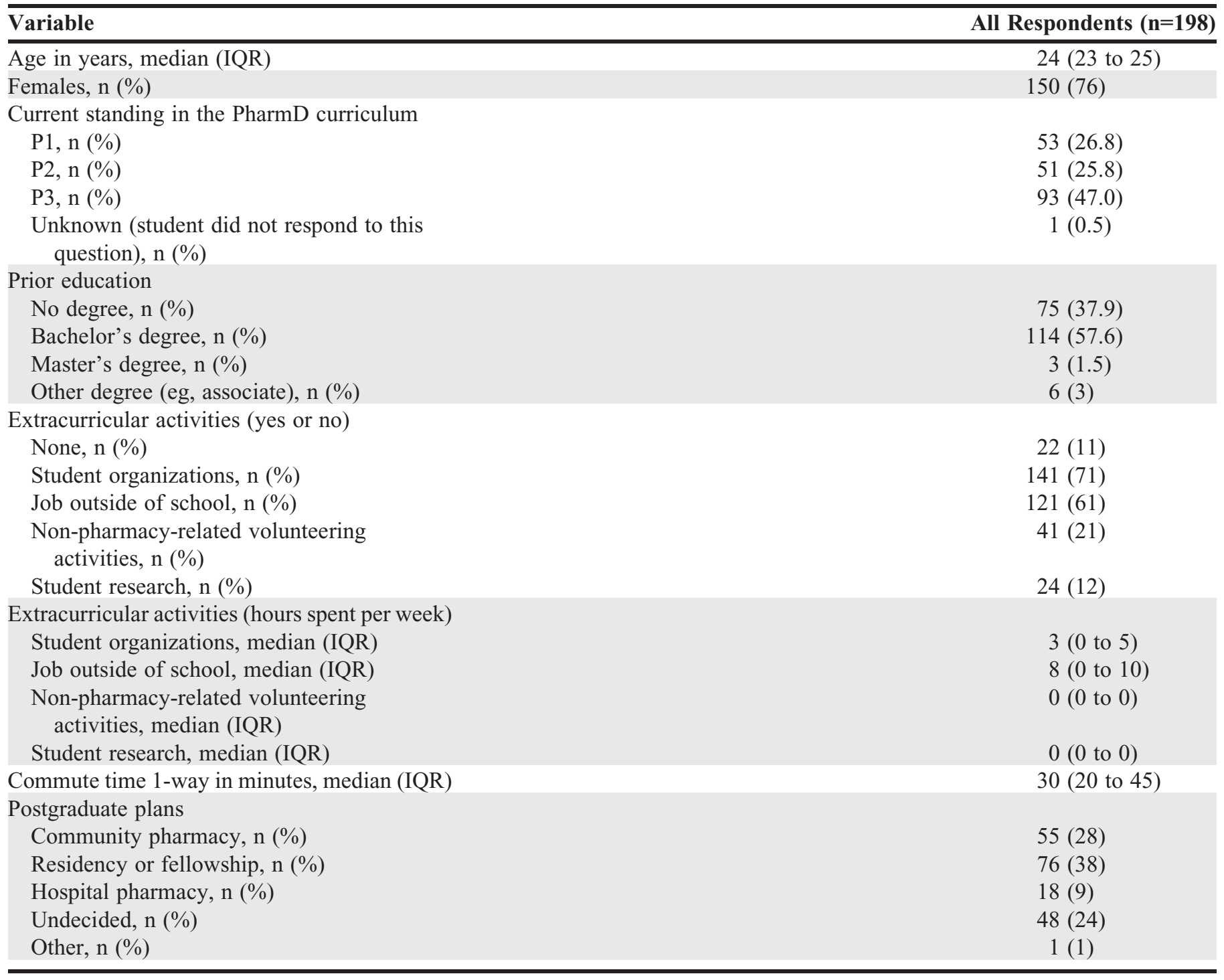

PharmD curriculum in which students have access to recorded lecture. Attitude and subjective norm were the most important constructs that predicted intention to attend lectures. This was demonstrated by the high correlation coefficients between direct measures of attitude and subjective norm with intention $\left(r_{s}>.7\right.$ for each), as well as by logistic regression in which attitude and subjective norm were predictors of high intention to attend lectures. These results are corroborated by previous reports that students were likely to attend lectures despite the availability of recordings if there was a perceived additional benefit of attendance (ie, positive attitude), such as having an engaging lecturer, doing interactive activities that aid in understanding and application of the material, or earning participation points for engaging in active-learning exercises. ${ }^{15,17,40}$
Similarly, a desire to demonstrate professionalism and fulfill the attendance expectations of professors (ie, positive subjective norm) have also been identified as major reasons for lecture attendance regardless of recording availability. ${ }^{4,11,14,15,17}$ In this study, perceived behavioral control was not a predictor of high intention to attend lectures. This could be because of the inadequacy of the survey in capturing this construct as the two items that directly measured perceived behavioral control had the lowest internal consistency. However, this finding is consistent with studies which showed that issues affecting students' abilities to attend lectures (ie, perceived behavioral control), such as competing priorities, have not been reported as major reasons for absenteeism in settings where recordings are available. ${ }^{4,14,15,17}$ 


\section{American Journal of Pharmaceutical Education 2020; 84 (5) Article 7550.}

Table 2. Modal Behavioral, Normative, and Control Beliefs of Doctor of Pharmacy Students Toward Attending Class Lectures Elicited During Focus Groups $(\mathrm{n}=9)$

\section{Beliefs}

Freq. n (\%)

Advantages of attending lecture (behavioral beliefs) ${ }^{\mathrm{a}}$

Able to interact with the lecturer (eg, ask questions

or network with)

Saves time when studying that material later

Lecture includes interactive exercises with relevant applications

Student's presence in lecture improves lecturer style, clarity, or ability to clarify questions ${ }^{b}$

Lecturer is enthusiastic and passionate

Observes lecturers' visual demonstrations ${ }^{\mathrm{b}}$

Able to interact with classmates (eg, ask questions or clarify points) ${ }^{\mathrm{b}}$

Disadvantages of attending lecture (behavioral beliefs) ${ }^{\mathrm{a}}$

Loses time that can be spent studying for an upcoming exam ${ }^{\mathrm{b}}$

Lecturer speaks too fast or too slow

Difficult to stay focused and attentive throughout entirety of lecture

Lecturer reads directly from slides

Loses sleep ${ }^{\mathrm{b}}$

Still a few lectures behind and is lost during the lecture $^{\mathrm{b}}$

Lecturer is unprepared or misspeaks during lecture ${ }^{\mathrm{b}}$

Interactive exercises are ineffective or not followed by debriefing ${ }^{\mathrm{b}}$

Lecturer skips slides ${ }^{b}$

Approve of attending lecture (normative beliefs) ${ }^{\mathrm{c}}$

Professors

Classmates

Disapprove of attending lecture (normative beliefs) ${ }^{\mathrm{c}}$

Classmates

Factors that facilitate attending lecture (control

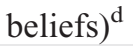

Pop or scheduled quizzes

Early morning classes ${ }^{\mathrm{b}}$

Free food available on the day of lecture

Factors that hinder attending lecture (control beliefs) ${ }^{\mathrm{d}}$

Commute and/or traffic

Early morning classes ${ }^{\mathrm{b}}$

Work and/or family obligations

Student organization meetings or events that occur during lectures

Lecture is scheduled close to an upcoming exam

Freq. $=$ frequency (number of times) a unique student mentioned a particular belief. Total number of students in focus groups $=9$

${ }^{a}$ Student responses to the following questions: What do you think might be advantages of attending lecture? What do you think might be disadvantages of attending lecture?

${ }^{\mathrm{b}}$ Belief was excluded from the final survey instrument distributed to the students to reduce respondent burden due to too few responses or lack of actionable intervention to improve attendance based on that belief

${ }^{\mathrm{c}}$ Student responses to the following questions: What individuals or groups would approve of you attending lecture? What individuals or groups would disapprove of you attending lecture?

${ }^{\mathrm{d}}$ Student responses to the following questions: What factors or circumstances enable your ability to attend lecture? What factors or circumstances hinder your ability to attend lecture? 


\section{American Journal of Pharmaceutical Education 2020; 84 (5) Article 7550.}

Table 3. Doctor of Pharmacy Students' Responses to a Survey That Evaluates Factors Influencing Their Intention to Attend Class Lectures

\begin{tabular}{|c|c|c|}
\hline Survey Item & Scale Range & Median (IQR) \\
\hline \multicolumn{3}{|l|}{ Intention } \\
\hline I intend to attend lecture next semester. & 1 to 7 & $5(4-7)$ \\
\hline \multicolumn{3}{|l|}{ Direct measures of attitude } \\
\hline $\begin{array}{l}\text { Attending lecture next semester is bad/good } \\
\text { for me. }\end{array}$ & 1 to 7 & $5(4-7)$ \\
\hline $\begin{array}{l}\text { Attending lecture next semester is useless/ } \\
\text { worthwhile. }\end{array}$ & 1 to 7 & $5(3-6)$ \\
\hline $\begin{array}{l}\text { Attending lecture next semester is } \\
\text { unpleasant/pleasant. }\end{array}$ & 1 to 7 & $4(4-6)$ \\
\hline Direct composite score of attitude ${ }^{a}$ & 3 to 21 & $15(11-18)$ \\
\hline \multicolumn{3}{|l|}{ Direct measures of subjective norm } \\
\hline $\begin{array}{l}\text { It is expected of me to attend lecture next } \\
\text { semester. (strongly disagree/strongly } \\
\text { agree) }\end{array}$ & 1 to 7 & $5(4-7)$ \\
\hline $\begin{array}{l}\text { Most people who are important to me think } \\
\text { I__attend lecture next semester. (should } \\
\text { not/should) }\end{array}$ & 1 to 7 & $5(4-7)$ \\
\hline Direct composite score of subjective norm ${ }^{\mathrm{a}}$ & 2 to 14 & $10(8-12)$ \\
\hline \multicolumn{3}{|l|}{ Direct measures of perceived behavioral control } \\
\hline $\begin{array}{l}\text { Whether I attend lecture next semester is } \\
\text { completely up to me. (strongly disagree/ } \\
\text { strongly agree) }\end{array}$ & 1 to 7 & $7(5-7)$ \\
\hline $\begin{array}{l}\text { I am confident that I can attend lecture next } \\
\text { semester if I wanted to. (strongly disagree/ } \\
\text { strongly agree) }\end{array}$ & 1 to 7 & $5(4-7)$ \\
\hline $\begin{array}{l}\text { Direct composite score of perceived } \\
\text { behavioral control }^{\mathrm{a}}\end{array}$ & 2 to 14 & $12(10-14)$ \\
\hline \multicolumn{3}{|l|}{$\begin{array}{l}\text { Indirect measures of attitude (behavioral } \\
\text { beliefs) }\end{array}$} \\
\hline $\begin{array}{l}\text { Attending lecture saves time when studying } \\
\text { that material later. }\end{array}$ & -21 to +21 & $6(3-15)$ \\
\hline $\begin{array}{l}\text { Attending lecture allows me to interact with } \\
\text { the lecturer (eg, ask questions or network). }\end{array}$ & -21 to +21 & $4.5(0-12)$ \\
\hline $\begin{array}{l}\text { If I attend lecture, there will be interactive } \\
\text { exercises with relevant applications. }\end{array}$ & -21 to +21 & $4(4-8)$ \\
\hline $\begin{array}{l}\text { I find it difficult to stay focused and attentive } \\
\text { throughout the entirety of lecture. }\end{array}$ & -21 to +21 & $-7(-15--3)$ \\
\hline $\begin{array}{l}\text { If I attend lecture, the lecturer is enthusiastic } \\
\text { and passionate. }\end{array}$ & -21 to +21 & $9(6-12)$ \\
\hline $\begin{array}{l}\text { If I attend lecture, the lecturer speaks at a } \\
\text { pace outside of my preferred speed. }\end{array}$ & -21 to +21 & $-8(-15--2)$ \\
\hline $\begin{array}{l}\text { If I attend lecture, the lecturer reads directly } \\
\text { from slides. }\end{array}$ & -21 to +21 & $-12(-18--5)$ \\
\hline \multicolumn{3}{|l|}{$\begin{array}{l}\text { Indirect measures of subjective norm } \\
\text { (normative beliefs) }{ }^{c}\end{array}$} \\
\hline $\begin{array}{l}\text { My professors think that } \mathrm{I} \_ \text {attend lecture } \\
\text { next semester. (should not/should) }\end{array}$ & -21 to +21 & $10(3-15)$ \\
\hline $\begin{array}{l}\text { My classmates would__of my attending } \\
\text { lecture next semester. (disapprove/ } \\
\text { approve) }\end{array}$ & -21 to +21 & $0(0-4)$ \\
\hline $\begin{array}{l}\text { Indirect measures of perceived behavioral } \\
\text { control (control beliefs) }{ }^{\mathrm{d}}\end{array}$ & & \\
\hline
\end{tabular}




\section{American Journal of Pharmaceutical Education 2020; 84 (5) Article 7550.}

Table 3. (Continued)

\begin{tabular}{llc}
\hline Survey Item & Scale Range & Median (IQR) \\
\hline $\begin{array}{l}\text { I expect to spend a significant amount of time } \\
\quad \text { commuting to attend lecture next semester. }\end{array}$ & -21 to +21 & $-12(-21-6)$ \\
$\begin{array}{l}\text { I expect pop quizzes during lecture next } \\
\quad \text { semester. }\end{array}$ & -21 to +21 & $5(0-12)$ \\
$\begin{array}{l}\text { I expect to have work or family obligations } \\
\text { that conflict with lecture next semester. }\end{array}$ & -21 to +21 & $-6(-14.25--3)$ \\
$\quad \begin{array}{l}\text { Student organization meetings or events will } \\
\text { occur during lectures next semester. }\end{array}$ & -21 to +21 & $-1(-3-0)$ \\
$\begin{array}{l}\text { I expect lectures will be scheduled close to an } \\
\text { upcoming examination next semester. }\end{array}$ & -21 to +21 & $-14(-21--6)$ \\
$\quad \begin{array}{l}\text { There will be free food and/or coffee offered } \\
\quad \text { in class next semester. }\end{array}$ & -21 to +21 & $3(0-6)$
\end{tabular}

${ }^{a}$ Sum of item scores within each construct

${ }^{\mathrm{b}}$ Indirect measure scores of attitude are weighted. Each behavioral belief strength is multiplied by the evaluation of the outcome. For example, the weighted score for "Attending lecture saves time when studying that material later" was calculated by multiplying the strength of this belief on a scale of 1 (unlikely) to 7 (likely) by the evaluation of the outcome on a scale of -3 (extremely undesirable) to +3 (extremely desirable)

${ }^{\mathrm{c}}$ Indirect measure scores of subjective norm are weighted. Each normative belief strength is multiplied by the motivation to comply with the referent individual or group. For example, the weighted score for "My professors think that I__attend lecture next semester" was calculated by multiplying the strength of this belief on a scale of -3 (should not) to +3 (should) by the motivation to comply with professors' expectation on a scale of 1 (not at all) to 7 (very much)

${ }^{\mathrm{d}}$ Indirect measure scores of perceived behavioral control are weighted. Each control belief's likelihood of occurring is multiplied by its power to hinder or facilitate attendance. For example, the weighted score for "I expect to spend a significant amount of time commuting to attend lecture next semester" was calculated by multiplying the likelihood of this belief occurring on a scale of 1 (unlikely) to 7 (likely) by its power to hinder or facilitate attendance on a scale of -3 (hindering) to +3 (enabling)

Our focus groups identified modal beliefs that have not been previously highlighted elsewhere in the literature, such as the perception that some classmates may disapprove if a student attends class (for instance, a student said "bitter people" who are behind in their studies may give someone who is doing well a hard time for attending class), free food being a motivating factor to attend lectures, and optional student organization meetings/events held during class time being a hindering factor to attend a lecture. One student perceived that one organization would show "a little bit of an attitude if [one] chooses to go to class" instead of the organization event. Another student said they would choose to attend an event instead of attending class. This poses several questions, including why students choose to go to an optional organizational event instead of attending class and whether such events should be allowed to be held during class time.
We sought to determine behavioral beliefs and normative beliefs that were predictive of students' attitudes and subjective norms, respectively, as these constructs were predictive of high intention to attend class lectures. Behavioral beliefs that were predictive of a favorable attitude towards attending lectures were the belief that attending lectures would result in having less study time for the material presented in that particular lecture and the belief that a lecture might include interactive exercises that had relevant applications. These beliefs suggest that possible interventions to improve attendance include making class truly a time for student learning and incorporating active-learning exercises that are relevant to examination questions and real-world practice. ${ }^{13}$ This can be achieved through various methods such as a flipped classroom approach, team-based learning, and problembased learning. ${ }^{13}$

Table 4. Correlation of Attitude, Subjective Norm, and Perceived Behavioral Control with Each Other and with Intention to Attend Class Lectures

\begin{tabular}{lcccc}
\hline & Intention & Attitude & Subjective Norm & Perceived Behavioral Control \\
\hline Intention & 1.00 & - & - & - \\
Attitude & $0.73^{\mathrm{a}}$ & 1.00 & - & - \\
Subjective norm & $0.76^{\mathrm{a}}$ & $0.79^{\mathrm{a}}$ & 1.00 & - \\
Perceived behavioral control & $0.41^{\mathrm{a}}$ & $0.40^{\mathrm{a}}$ & $0.38^{\mathrm{a}}$ & 1.00 \\
\hline
\end{tabular}

Data presented as Spearman's rho. ${ }^{\text {a }}$ Correlation is significant at $p<.01$ 


\section{American Journal of Pharmaceutical Education 2020; 84 (5) Article 7550.}

Table 5. Multiple Logistic Regression Model of the Contribution of Attitude, Subjective Norm, and Perceived Behavioral Control in Predicting High Intention to Attend Class Lectures (Intention Response of $>5$ out of 7 )

\begin{tabular}{lccr}
\hline Independent Variable & Adjusted Odds Ratio & $\mathbf{9 5 \%}$ Confidence Interval & $\boldsymbol{p}$ value \\
\hline Attitude & 1.28 & $1.11-1.47$ & $<.001$ \\
Subjective norm & 1.66 & $1.31-2.11$ & $<.001$ \\
Perceived behavioral control & 1.14 & $0.94-1.38$ & .179 \\
\hline
\end{tabular}

Hosmer-Lemeshow goodness-of-fit test $p=.649$

Two normative beliefs (perceived expectations of professors and classmates regarding attendance) were predictive of a strong positive subjective norm. This suggests that increasing "social pressure" to attend class lectures via an attendance policy or by instituting a culture change such that attendance becomes the norm would improve attendance. Whether attendance should be mandated is beyond the scope of this paper. Previous papers have highlighted arguments for both sides, but all agree that attendance does not equate learning. ${ }^{41-43}$

In summary, this study highlighted the determining factors when students weigh all the "costs" and "benefits" of attending class. The fact that perceived behavioral control was not predictive of intention suggests that behavioral and normative beliefs that shape students' attitudes and subjective norm may be more important determinants of attendance than control beliefs that facilitate attendance (eg, pop quizzes) or control beliefs that hinder attendance (eg, long commute). If lectures are valuable to students' learning and attendance is expected and/or part of the culture at a college, this study suggests students most likely will attend class despite control beliefs that may hinder their ability to do so (eg, commute, early morning class, work/family obligations).

This study has limitations. First, biases intrinsic to surveybased research are possible, such as social desirability, self-reporting, and non-response biases. Second, using actual lecture attendance as a dependent variable in the study would have been ideal but was not possible because attendance was not routinely monitored. Third, students reported their intention to attend lectures in general, but it is likely that a student's actual lecture attendance varies from course to course. Additionally, third-year students represented half of the respondents, but a post-hoc analysis revealed that findings were not different when third-year students were excluded. Fourth, the single-center nature of this study limits the external validity of the results. Compared to students nationally who were enrolled in a PharmD program in fall 2017, a greater percentage of our respondents were female ( $76 \%$ vs $63 \%)$ and held a prior bachelor's degree (58\% vs $39 \%) .{ }^{44}$ Finally, the lack of association between perceived behavioral control and intention might be a true finding or the result of inadequate capture of this construct.

\section{CONCLUSION}

The theory of planned behavior model was used to determine the main predictors of students' intention to attend lectures in a PharmD program in which asynchronous lecture recordings were available. Attitude and subjective norm were most predictive of students' high intention to attend lectures. These findings may inform the development of interventions aimed at increasing the perceived advantages of attending lectures and "social pressure" from professors and classmates to attend lectures. Future studies are needed to assess the impact of such interventions on actual student lecture attendance.

\section{REFERENCES}

1. Mattick K, Crocker G, Bligh J. Medical student attendance at noncompulsory lectures. Adv Health Sci Educ Theory Pract. 2007;12(2):201-210.

2. Nast A, Schafer-Hesterberg G, Zielke H, Sterry W, Rzany B. Online lectures for students in dermatology: a replacement for traditional teaching or a valuable addition? J Eur Acad Dermatol Venereol. 2009;23(9):1039-1043.

3. Rejno A, Nordin P, Forsgren S, Sundell Y, Rudolfsson G. Nursing students' attendance at learning activities in relation to attainment and passing courses: a prospective quantitative study. Nurse Educ Today. 2017;50:36-41.

4. Westrick SC, Helms KL, McDonough SK, Breland ML. Factors influencing pharmacy students' attendance decisions in large lectures. Am J Pharm Educ. 2009;73(5):83.

5. Kassarnig V, Bjerre-Nielsen A, Mones E, Lehmann S, Lassen DD. Class attendance, peer similarity, and academic performance in a large field study. PloS one. 2017;12(11):e0187078.

6. Riggs JW, Blanco JD. Is there a relation between student lecture attendance and clinical science subject examination score? Obstet Gynecol. 1994;84(2):311-313.

7. Leufer T, Cleary-Holdforth J. Reflections on the experience of mandating lecture attendance in one school of nursing in the Republic of Ireland. AISHE-J. 2010;2(1):1-14.

8. Moore S, Armstrong C, Pearson J. Lecture absenteeism among students in higher education: a valuable route to understanding student motivation. J High Educ Pol Manag. 2008;30(1):15-24. 9. Horton DM, Wiederman SD, Saint DA. Assessment outcome is weakly correlated with lecture attendance: influence of learning style and use of alternative materials. Adv Physiol Educ.

2012;36(2):108-115.

10. Azab E, Saksena Y, Alghanem T, et al. Relationship among dental students' class lecture attendance, use of online resources, and performance. J Dental Educ. 2016;80(4):452-458. 


\section{American Journal of Pharmaceutical Education 2020; 84 (5) Article 7550.}

11. Eisen DB, Schupp CW, Isseroff RR, Ibrahimi OA, Ledo L, Armstrong AW. Does class attendance matter? Results from a second-year medical school dermatology cohort study. Int $J$ Dermatol. 2015;54(7):807-816.

12. Marchand JP, Pearson ML, Albon SP. Student and faculty member perspectives on lecture capture in pharmacy education. $\mathrm{Am} \mathrm{J}$ Pharm Educ. 2014;78(4):74.

13. Stoner SC, Fincham JE. Faculty role in classroom engagement and attendance. Am J Pharm Educ. 2012;76(5):75.

14. Bati AH, Mandiracioglu A, Orgun F, Govsa F. Why do students miss lectures? A study of lecture attendance amongst students of health science. Nurse Educ Today. 2013;33(6):596-601.

15. Billings-Gagliardi S, Mazor KM. Student decisions about lecture attendance: do electronic course materials matter? Acad Med. 2007;82(10 Suppl):S73-76.

16. Cardall S, Krupat E, Ulrich M. Live lecture versus videorecorded lecture: are students voting with their feet? Acad Med. 2008;83(12):1174-1178.

17. Gupta A, Saks NS. Exploring medical student decisions regarding attending live lectures and using recorded lectures. Med Teach. 2013;35(9):767-771.

18. Maynor LM, Barrickman AL, Stamatakis MK, Elliott DP. Student and faculty perceptions of lecture recording in a doctor of pharmacy curriculum. Am J Pharm Educ. 2013;77(8):165.

19. McNulty JA, Hoyt A, Gruener G, et al. An analysis of lecture video utilization in undergraduate medical education: associations with performance in the courses. BMC Med Educ. 2009;9:6.

20. Persky AM. The impact of team-based learning on a foundational pharmacokinetics course. Am J Pharm Educ. 2012;76(2):31. 21. Freeman S, Eddy SL, McDonough M, et al. Active learning increases student performance in science, engineering, and mathematics. PNAS. 2014;111(23):8410-8415.

22. Remington TL, Bleske BE, Bartholomew T, et al. Qualitative analysis of student perceptions comparing team-based learning and traditional lecture in a pharmacotherapeutics course. Am J Pharm Educ. 2017;81(3):55.

23. Stewart DW, Brown SD, Clavier CW, Wyatt J. Active-learning processes used in US pharmacy education. Am J Pharm Educ. 2011;75(4):68.

24. Grant C, Osanloo A. Understanding, selecting, and integrating a theoretical framework in dissertation research: creating the blueprint for your "house." Administrative Issues Journal: Connecting Education, Practice, and Research. 2014;4(2):12-26.

25. White KM, Thomas I, Johnston KL, Hyde MK. Predicting attendance at peer-assisted study sessions for statistics: role identity and the theory of planned behavior. J Soc Psychol. 2008;148(4):473-491.

26. Taylor RC. Using the theory of planned behaviour to understand students' subject choices in post-compulsory education. Res Papers Educ. 2015;30(2):214-31.

27. Sugar W, Crawley F, Fine B. Examining teachers' decisions to adopt new technology. Educ Tech Society. 2004;7(4):201-13.

28. Ajzen I. The theory of planned behavior. Org Behav Hum Decis Process. 1991;50(2):179-211.
29. Azjen I. Theory of planned behavior with background factors. https:// people.umass.edu/aizen/tpb.background.html. Accessed April 30, 2020. 30. Creswell JW, Plano Clark VL. Designing and Conducting Mixed Methods Research. 3rd edition. Los Angeles, CA: SAGE Publications, Inc.; 2017.

31. Francis J, Eccles MP, Johnston M, et al. Contructing questionnaires based on the theory of planned behaviour: a manual for health services researchers. http://openaccess.city.ac.uk/1735/. Accessed April 30, 2020.

32. Sutton S, French DP, Hennings SJ, et al. Eliciting salient beliefs in research on the theory of planned behaviour: the effect of question wording. Curr Psych. 2003;22(3):234-251.

33. Fleming ML, Barner JC, Brown CM, Shepherd MD, Strassels S, Novak S. Using the theory of planned behavior to examine pharmacists' intention to utilize a prescription drug monitoring program database. Res Social Adm Pharm. 2014;10(2):285-296. 34. Gavaza P, Brown CM, Lawson KA, Rascati KL, Wilson JP, Steinhardt M. Influence of attitudes on pharmacists' intention to report serious adverse drug events to the Food and Drug Administration. Br J Clin Pharmacol. 2011;72(1):143-152. 35. Ajzen I, Fishbein M. Understanding Attitudes and Predicting Social Behaviour. 1st edition. Englewood Cliffs, NJ: Prentice Hall; 1980. 36. Dillman DA, Smyth JD, Christian LM. Internet, Mail, and Mixed-Mode Surveys: The Tailored Design Method. 3rd edition. Hoboken, NJ: John Wiley \& Sons; 2009.

37. Elo $\mathrm{S}, \mathrm{Kyngas} \mathrm{H}$. The qualitative content analysis process. $J A d v$ Nurs. 2008;62(1):107-115.

38. Fleming ML, Bapat SS, Varisco TJ. Using the theory of planned behavior to investigate community pharmacists' beliefs regarding engaging patients about prescription drug misuse. Res Social Adm Pharm. 2019;15(8):992-999.

39. Robinson JP, Shaver PR, Wrightsman LS. Criteria for scale selection and evaluation. Measures Personal Soc Psychol Attitudes. 1991;1:1-16.

40. Topale L. The strategic use of lecture recordings to facilitate an active and self-directed learning approach. BMC Med Educ. 2016;16(1):201.

41. Cutler CW, Parise M, Seminario AL, Mendez MJ, Piskorowski W, Silva R. Should attendance be required in lecture classrooms in dental education? Two viewpoints: viewpoint 1: attendance in the lecture classroom should be required and viewpoint 2: attendance should not be required in the lecture classroom. $J$ Dent Educ. 2016;80(12):1474-1478. 42. Lipscomb M, Snelling PC. Student nurse absenteeism in higher education: an argument against enforced attendance. Nurse Educ Today. 2010;30(6):573-578.

43. Lach MK, McCarthy BC, Jr.. Student and faculty member perspectives on lecture capture in pharmacy education. Am J Pharm Educ. 2015;79(8):126.

44. American Association of Colleges of Pharmacy. Profile of pharmacy students fall 2017. https://www.aacp.org/sites/default/files/ 2018-05/fall-2017-profile\%20of\%20pharmacy\%20studentsintroduction.pdf. Accessed April 30, 2020. 